\title{
CONTRIBUIÇÕES DOS ESTUDOS DO COTIDIANO À REFLEXÃO SOBRE SER/TORNAR- SE ESTUDANTE: PERTENCIMENTO E EXCLUSÃO NO ESPAÇO-TEMPO DA ESCOLA
}

\author{
P. A. CASTRO ${ }^{1}$, M. CAETANO ${ }^{2, *}$, T. E. S. GOULART ${ }^{3}$, A. M. A. CASTRO ${ }^{4}$ \\ ${ }^{1}$ Universidade Estadual da Paraíba - UEPB, ${ }^{2,4}$ Universidade Federal do Rio Grande - FURG, ${ }^{3}$ Universidade Federal \\ Fluminense - UFF \\ mrvcaetano@gmail.com*
}

Submetido 10/2016 - Aceito 25/09/2018

DOI: $10.15628 /$ holos.2018.5257

\section{RESUMO}

Neste artigo, debateremos os sentidos produzidos em torno das vivências escolares por estudantes com dificuldades de leitura e escrita de uma escola pública do estado da Paraíba. Para tanto, foi utilizada a abordagem dos estudos do cotidiano para compreender os sentidos dos fazeres, deveres e saberes conduzidos/as pelos/as discentes em torno do processo de ser/tornar-se estudante. Os resultados apontam para a compreensão de que os processos de aprender e ensinar apresentam-se imbricados pela construção de sentidos à permanência na escola e sentimentos de pertença que não se encerram nos conteúdos disciplinares dispostos nos currículos. Dessa forma, é nossa intenção questionar os mecanismos sutis de exclusão escolar e, nesse sentido, refletir sobre o papel da escola em uma perspectiva inclusiva.

PALAVRAS-CHAVE: Estudos do cotidiano; Identidade; Exclusão.

\section{CONTRIBUTIONS OF DAILY LIFE STUDIES ON THE REFLECTION ABOUT BE/BECOMING A STUDENT: BELONGING AND EXCLUSION IN SCHOOL SPACE/TIME} \begin{abstract}
In this article, we will discuss the meanings produced by students with reading and writing difficulties of a public school in the state of Paraiba around their school experiences. Therefore, we used the daily life studies' approach in order to understand the meanings around the doings, duties and knowledges conducted by the students about the process of being/ becoming a student. The results point to understanding the
\end{abstract}

processes of learning and teaching as imbricated by the construction of reasons to remain in school and a sense of belonging that are not restricted to the disciplinary contents arranged in the curriculum. Thus, it is our intention to question the subtle mechanisms of exclusion from school and, at the same time, to reflect on the role of the school from a truly inclusive perspective.

KEYWORDS: Daily life studies; Identity; Exclusion. 


\section{INTRODUÇÃO}

O texto apresenta os resultados do estudo sobre os processos de tornar-se estudante, as formas de pertencimento e resiliência expressos pelos próprios sujeitos nas explicações sobre as práticas escolares que envolvem a ação pedagógica dos processos de escolarização. A pesquisa envolvendo discentes busca, na perspectiva dos pressupostos dos estudos dos os cotidianos, o sujeito como principal interlocutor para a produção de dados que ajudem a problematizar o cenário vivido. Além disso, estudos de autores como Castro (2016); Steinberg e Kincheloe (1997) destacaram a importância da participação de estudantes como sujeitos da pesquisa para informar sobre as políticas e práticas educacionais em suas dimensões cotidianas.

A pesquisa foi orientada para a construção de um quadro referencial que interrogasse os desdobramentos dos processos educacionais coletivamente construídos para serem adaptados a vivências e experiências daqueles que se tornaram estudantes com vistas ao favorecimento de escolhas profissionais. Entendemos que é pela dinâmica das interações entre os processos educacionais e seus atores que é produzido o conhecimento no qual a pesquisa deseja contribuir com explicações e compreensão sobre os fenômenos sociais observados neste espaço-tempo. Assim, acreditamos em virtude dos usos que os sujeitos fazem da escola, bem como das relações que estabelecem a partir das noções de pertencimento e criação da identidade "estudante". Como parte dos resultados, apresentamos a análise dos dados realizada a partir da produção de discentes ${ }^{1}$ do 60 ano do Ensino Fundamental sobre suas perspectivas acerca das trajetórias escolares vividas e apresentadas por meio de respostas objetivas as perguntas feitas pela equipe de investigação.

O estudo foi desenvolvido em uma escola da rede estadual de ensino na cidade de Campina Grande - Paraíba. Localizada na região central da cidade, a instituição atende ao segmento do Ensino Fundamental e conta com cerca de oitocentos estudantes, divididos em vinte e três turmas atendidas nos três turnos: sendo o período noturno reservado às turmas da modalidade da Educação de Jovens e Adultos e o período diurno à modalidade regular.

O corpo docente é composto por 21 professoras e 8 professores, totalizando 29 docentes, entre 25 e 50 anos, sendo que duas são regentes das turmas de Anos Iniciais do Ensino Fundamental - primeiro ao quinto ano - e vinte e sete dos Anos Finais - sexto ao nono ano. Todos/as profissionais citados/as são habilitados/as para exercer a docência em seus referentes níveis: tem formação em Licenciatura Plena em Pedagogia ou em disciplinas isoladas. As visitas à escola foram realizadas entre os meses de agosto e outubro de 2015, ocorrendo majoritariamente às quartas-feiras, e detinham-se principalmente às aulas de matemática, em decorrência da autorização da professora e suas seguidas queixas sobre o rendimento escolar discente.

A sala escolhida para a pesquisa foi o sexto ano do Ensino Fundamental (antiga quinta série), do turno da tarde. Composta por 22 estudantes: 11 meninos e 11 meninas de idades díspares ao ano estudado. Contudo, para esse texto iremos citar apenas as narrativas de 6 estudantes e da professora, considerando os objetivos que, em seguida, serão apresentados.

\footnotetext{
${ }^{1}$ Os nomes dos sujeitos da pesquisa foram alterados respeitando os critérios de ética na pesquisa com seres humanos (BRASIL, 510/2016)
} 
Mas vale destacar que a escolha da turma, além daquelas já ditas, deveu-se à peculiaridade de que o conjunto de discente apresenta dificuldades no processo de aprendizagem, são repetentes e vários/as oriundos/as da rede municipal de ensino, que adota uma perspectiva de formação diversa à rede estadual. Há registros de estudantes que são acompanhados pelo Conselho Tutelar da cidade por problemas familiares, envolvimento com drogas ilícitas, dentre outras questões descritas como problemáticas pela equipe diretiva.

Conforme uma das professoras entrevistadas, a formação da turma especial na qual estavam os/as estudantes com demandas específicas ocorreu no início do ano letivo porque quando inseridos/as nas classes regulares foram diagnosticados/as como impossibilitados/as de acompanhar o ritmo esperado da $6^{a}$. série. A estratégia de criação de turmas de aceleração ${ }^{2}$ na escola investigada motiva-se pela necessidade dos/das estudantes adquirem os conteúdos elementares para que, deste modo, possam ser favorecidos/as e reintegrados/as às turmas padronizadas.

Feita a descrição panorâmica do cenário e sujeitos da investigação, destacamos que as asserções teóricas serão apresentadas para a compreensão sobre as trajetórias de ser e/ou torna-se estudante, contemplando os aspectos teórico-epistemológicos e metodológicoempíricos. O enfoque teórico-epistemológico relaciona-se à produção científica sobre a/o estudante em suas múltiplas possibilidades, enquanto o metodológico-empírico alinha os pressupostos instrumentais e analíticos sobre a investigação baseada na abordagem dos estudos do cotidiano da escola e da sala de aula. Para o desenvolvimento da pesquisa foram propostos os seguintes objetivos:

I. compreender os processos de pertencimento discente ao espaço escolar;

II. debater os sentidos produzidos em torno das vivências escolares por estudantes com dificuldades de leitura e escrita de uma escola pública do estado da Paraíba

A investigação pautou-se, ainda, nas seguintes questões de pesquisa:

I. Quais as instâncias e instrumentos presentes nas vivências cotidianas das escolas que os estudantes destacaram como fundamentais para o desenvolvimento de suas aprendizagens?

II. Como os sujeitos construíram suas identidades de estudante considerando as formas com que interagem e se apropriam das dinâmicas escolares?

Com a definição dos objetivos e as questões de pesquisa, apresentam-se, neste artigo, os resultados a partir dados produzidos com o cotidiano da escola e das/os discentes.

\section{MICHEL DE CERTEAU, OS ESTUDOS DO COTIDIANO ESCOLAR E O SER/TORNAR-}

\section{SE ESTUDANTE}

\footnotetext{
${ }^{2}$ Conforme Sousa (1999), os programas de classes de aceleração de aprendizagem são destinados a estudantes com defasagem série/idade que estão retidos nas séries iniciais do ensino fundamental ou que foram evadidos da escola antes de concluírem as quatro séries iniciais. Essas turmas buscam "oferecer condições para que os alunos, ao receberem um ensino planejado que atenda suas peculiaridades, possam avançar no processo de escolarização, integrar-se na escola e vir a frequentar séries compatíveis com sua faixa etária" (p. 82).
} 
Michel Certeau (1994), em seu livro "A invenção do cotidiano", explana que a vida cotidiana não é um tema muito nobre para as Ciências Humanas e, há poucos anos, ela passou a ter atenção. $\mathrm{O}$ autor destaca que o campo das Ciências Humanas e Sociais, de várias correntes teóricas, não percebe a vida cotidiana como um espaço repleto de inventividade; tampouco percebem que a teorização, a partir do cotidiano, leva a uma produção cultural anônima, desenvolvida com a criatividade de pessoas comuns, e as narrativas do cotidiano das pessoas estão mais próximas da intensidade da vida real. Por isso, reconhecendo a relevâncias das observações feitas por Certeau, que a abordagem dos estudos do cotidiano foi escolhida por permitir uma postura dialógica, interessada e de curiosidade frente aos modos como os sujeitos se apropriam dos espaços-tempos que ocupam e, nessa relação, vão construindo suas subjetividades em articulação com as ordens, leis e regulações com as quais interacionam.

Para essa situação nos lembra Certeau (1994), naquilo que o autor afirma acerca dos/as agentes opressivos/as e a interpretação de suas leis, ordens e regulações. Para ele, o/a emissor/a da mensagem não é capaz de determinar a forma como suas leis serão consumidas, por isso, elas são dribladas ou redimensionadas. Portanto, não é o/a fabricante que determina o uso, nem tampouco o/a opressor/a que estabelece a forma e o comportamento que suas regras irão estabelecer naqueles/as para os quais se destinam, mas o/a consumidor/a, que como receptor da ordem, estabelece a sua interpretação. Na tática dos/das praticantes o "eu" fica em segundo plano, a previsão de ações passa ser definida pelas ações que, especuladas ou não, são produzidas pelo/a outro/a: aquele que tem o poder de definir estratégias.

Segundo Certeau (1994), os comandos e definições acerca dos sujeitos não são meras ações descritas pela voz. Não existe voz "pura" de intenções. Ela é sempre determinada por sistemas de interesses. Deste modo, o que é relatado em uma sociedade escriturária (a que define as regras) é fruto do seu meio e é capaz de transformar a carne (sujeito sem as normas coletivas) em um corpo social, portanto, reconhecido. Assim, a escola também assume o papel central em estabelecer o inscrito na construção dessa carne que, tatuado às normas, transformao de corpo individual para corpo social. Isso não significa que a escola seja capaz de determinar os lugares sociais e as formas como o corpo social irá transitar em suas relações, entretanto, os níveis de legitimidade social que possui e a autoridade de atestar a escolaridade e os conhecimentos adquiridos fazem que escola tenha relevância na arte de construir corpos sociais.

Essa perspectiva, a partir de um viés transdisciplinar, possibilitou-nos questionar os modos possíveis à construção do conhecimento e um olhar sensível à complexidade rizomática que vai conformando o que interpretamos como a realidade do cenário escolar. Como apreendemos com Regina Leite Garcia (2001; 2003), Inês Barbosa de Oliveira (2007) e Nilda Alves (2001; 2010), o cotidiano é o espaço de permanente negociação em que a vida acontece, com todas as suas contradições e desigualdades. Conforme Garcia nos adverte:

\footnotetext{
O cotidiano é a hora da verdade. É ali que os grandes projetos, as grandes explicações, as grandes sínteses, as grandes narrativas e as grandes certezas são confirmadas ou negadas, e o que complica ainda mais é que às vezes a mesma certeza que num momento é confirmada, no momento seguinte, é negada. É ali, no cotidiano que sujeitos encarnados lutam, sofrem, são explorados, subalternizados, resistem, usam astúcias para se defender das estratégias dos poderosos, se organizam para sobreviver, e assim vivem, lutam, sobrevivem e, como todos os mortais, um dia morrem. Não esquecendo que uns morrem antes do que outros, dadas as condições de vida, no limite da morte, a que estão expostos (GARCIA, 2003, p. 195).
} 
Por essa razão, trabalhar no e com o cotidiano exige a "criação e reinvenção permanente dos saberes/fazeres/valores e emoções" (OLIVEIRA, 2007, p. 59). Ou, ainda, como nos provoca Alves (2001, p. 15), "a trajetória de um trabalho no cotidiano precisa ir além do que foi aprendido com essas virtualidades da modernidade, na qual o sentido da visão foi exaltado [...]". É preciso fazer do mergulho, do não se abrigar à segurança de suposta objetividade/afastamento a metodologia que orienta o trabalho no sentido que perceber o cotidiano em sua riqueza, multiplicidade e contradição.

Para tanto, Alves (2001) nos sugere que atentemos para quatro movimentos reflexivos para a compreensão do cotidiano. O primeiro movimento, "sentimento do mundo", exige a postura de "querer saber mais", considerando também enquanto sujeito notadamente envolvido na produção do conhecimento científico. Nesse sentido, enquanto ente em uma relação, o/a pesquisador deve conhecer suas próprias limitações e reconhecer que a pesquisa sob esse viés exige o estabelecimento de redes múltiplas de relações entre quem pesquisa e as problemáticas a serem enfrentadas, entre pesquisador/a e os sujeitos dos contextos pesquisados e entre o/a investigador/a, os sujeitos com que se dialoga e outros quem esses (con)vivem.

O segundo movimento proposto nos instiga a virar de ponta cabeça o modo como aprendemos a produzir saber na academia. Nessa direção, Alves (2001) salienta utilização de teorias várias enquanto meras hipóteses a serem negadas e limites que nos permitem ir somente até determinado ponto, exigindo criatividade para prosseguir. Por essa razão, com o terceiro movimento a autora apresenta a crítica à lógica de pensamento hierárquica e atomizante outorgada pela modernidade e sublinha a necessidade de bebermos em todas as fontes para construir outra práticateoriaprática. Para ela,

[...] em nenhum caso, existem práticas não articuladas com teorias: parte-se de práticas para formular teorias que só se mantêm quando voltam a se 'realizar' em práticas. Dessa maneira, afirmamos que todo praticante é um pensador, pois articula, a partir de suas práticas, propostas para modificá-las, produzindo metodologias, ideias e valores, a cujo momento poderíamos chamar 'teorias'. A esse movimento vimos chamando práticateoriaprática (ALVES, 2010, 71).

É possível apreender que para a autora, é notória a existência de múltiplas fontes, abordagens, interpretações e múltiplos sentidos, caminhos ou afetos. Entretanto, tal imensa variedade não é, por si só, sinônimo de complexidade. Essa exige uma "posição teóricometodológica em criação" (ALVES, 2001, p. 25) e a tessitura de um pensamento em rede que se resista à linearidade, ao disciplinamento e à hierarquização. Nessa mesma direção, os escritos de Regina Leite Garcia (2003) corroboram com esta pesquisa quando a autora afirma que é "impossível investigar o cotidiano pres@ aos limites da visão disciplinar, pois, se assim o fazemos, da realidade veremos apenas o que o nosso estreito ponto de vista unidisciplinar nos permite ver" (p. 196).

Logo, novamente percebemos a relevância do quarto movimento apresentado por Nilda Alves: narrar a vida e literaturizar a ciência. Ou seja, há uma outra escritura, que se expresse por múltiplas linguagens, a se aprender. Nesses termos, é necessário o redirecionamento do olhar para além das fontes escritas/oficiais hegemonicamente aceitas. Para além disso, ao se fazer uso de narrativas, a abordagem dos estudos nos/dos/com o cotidiano as percebem não apenas como fontes ou recursos metodológicos, mas as transformam em personagens conceituais (ALVES, 2010). 
Nessa pesquisa, em destaque, as possibilidades apresentadas pelos estudos no/do/com os cotidianos foram dimensionadas tanto nas narrativas apresentadas em forma de redação quanto nos desenhos dos/as estudantes e auxiliaram na compreensão sobre os processos de construção da realidade interpretada em sala de aula. Assim, a investigação foi acompanhada, a todo tempo, por múltiplos movimentos que envolviam pesquisadora-estudantes, pesquisadoradocentes/gestão escolar e pesquisadora-discentes-gestora da escola e que foram capazes de produzir conhecimento acerca das formas cotidianas com que os sujeitos de diferentes culturas e/ou contextos vivenciam e se percebem em seus contextos.

A gama de diversidade e projeções que os sujeitos são capazes de assumir ao longo de suas existências cotidianas são múltiplas e acabam sendo suas narrativas o meio por onde os sujeitos se experimentam e configuram suas identidades (DELORY-MOMBERGER, 2008). Nessa direção, concordamos com Hall (2003), quando o autor afirma que o saber sobre algo e/ou alguém será sempre parcial, que a realidade é uma construção e a identidade é sempre um estado em processo. Com isto, as discussões sobre a identidade estão circunscritas ao tempo/espaço da trajetória narrada.

As discussões neste texto operaram para acolá do descentramento e/ou deslocamento dos sujeitos em suas múltiplas performances identitárias, como nos chama a atenção Hall (2003), e preocuparam-se com as condições de possibilidades de determinadas práticas que produziram inteligibilidades sobre a identidade "estudante" produzida pelos sujeitos dessa pesquisa. Nas discussões, não deixamos de observar como o entendimento de determinado discurso sobre a identidade "estudante" operaram como verdade, provocando alterações e produções nos sujeitos. Pensamos que elas, configuraram o que Hall afirmou sobre identidade. Segundo ele,

[...] o sujeito assume identidades diferentes em diferentes momentos, identidades que não são unificadas ao redor de um "eu" coerente. Dentro de nós há identidades contraditórias, empurrando em diferentes direções, de tal modo que nossas identificações estão sendo continuamente deslocadas (HALL, 2003, p.13).

Desta forma, quando nos debruçamos sobre o conceito de identidade/identificação o fazemos o percebemos como não estático, devido aos diversos usos e performances que escolhemos/somos convocadas/os a fazer dele. Sendo assim, as noções de identidade tensionaram os caminhos da pesquisa ditando os momentos de equilíbrio e desequilíbrio na relação com outros sujeitos. Nesses momentos, exercitamos o rigor flexível que nos apontam as pesquisas de Regina Leite Garcia. Da mesma forma, a relação com a escola - seu espaço-tempo e sujeitos que o constroem - exigiu o cuidado, a atenção, a delicadeza, a sensibilidade para o outro" (GARCIA, 2001, p. 18) visto como legítimo outro e o qual não desejo tornar-me.

\section{SER/TORNAR-SE ESTUDANTE NA CONTEMPORANEIDADE}

A compreensão sobre as influências das práticas escolares no processo de ser/tornar-se estudante envolve o processo de construção do sentimento de pertença e sua relação com o espaço escolar. Neste sentido, é possível apontar que é por meio do pertencimento que as/os estudantes podem legitimar suas identidades em seus diferentes contextos de convivência, sobretudo na escola. 
Entendemos, portanto, que, por meio do compartilhamento de experiências, vivências e características com outros sujeitos que compõem as comunidades as quais se integra, é possível se desenvolver o sentimento de pertença àquele grupo. Com Sarmento (2002), podemos compreender que o pertencimento é constituído pelas relações comunitárias; construções de referências; valores de pauta de condutas e distribuição de poderes que são inerentes à pertença comunitária (p. 11). Desta maneira, a partir das interações em sala de aula são criados significados e sentidos que permeiam a escola e que revelam seu cotidiano: descritos, no geral, pelos/as estudantes como um espaço de tarefas, aprendizagem de conhecimento, normas e castigos.

Considerando as apresentações dos/das estudantes descrito anteriormente, salientamos que as interações estabelecidas na escola investigada: seja entre docentes e estudantes e destes entre si, se configuraram como representações acionadas pela memória sobre a sala de aula, corroborando com o que Delamont (1987) definiu ser a interação escolar. Para a autora, configura-se como um "processo que vai avançando e mediante o qual as realidades de todos os dias da sala de aula são constantemente definidas e redefinidas" (p.39). Neste sentido, é plausível considerar que a escola - sala de aula - não se institui como um espaço de saber sem que os sujeitos escolares nela estivessem incluídos para a construção colaborativa dos sentidos sobre esse espaço.

A partir da análise de dados, foi possível apreender tais significações e representações para as/os estudantes e, com elas, buscamos compreender a influência das práticas desdobradas na escola sobre o sentimento de pertença dos sujeitos ao espaço escolar. O estudante Rômulo, em setembro de 2015, quando solicitado a descrever seu entendimento sobre "ser estudante", escreveu que gosta de estudar, acrescentando que "a pessoa sem estudo, não é nada". Rômulo, era um dos estudantes que durante as aulas interagia com os/as demais, mas não desenvolvia as atividades solicitadas pela professora de matemática, Catarina. Por muitos momentos, buscava chamar a atenção de seus/suas colegas com piadas e músicas, desconcentrando a turma no desenvolvimento de suas atividades e muito vezes assumindo a centralidade de "diálogo" com a professora Catarina, quando ela chamava a atenção deste.

Sobre a importância de estudar, enfatizada por Rômulo, ainda é presente no imaginário social a necessidade de que "para ser alguém na vida é preciso estudar". Ser escolarizado/a é um processo que demanda um sem-número de astúcias que o/a estudante utiliza na criação de táticas ao longo dos anos para permanecer na escola. Conforme compreendemos com o caso de Roberto, o processo de pertencimento ao espaço escolar tal como as interações com os demais colegas da sala desempenha um papel relevante na permanência e na construção de sentidos em torno do processo de formação escolar. Neste sentido, compreendemos que a exclusão social e os mecanismos que culminam em baixa escolarização - que podemos mencionar aqui através do "fracasso escolar" - estabelecem entre si uma interface que desconsidera os inúmeros aspectos e a amplitude que compõe o quadro excludente em que a sociedade atual está calcada.

Nesse cenário, é atribuído exclusivamente à escola o dever de tornar o/a estudante, por meio da escolarização atestada somente por ela, um sujeito apto a integrar a sociedade e, desta forma, ser considerado "alguém na vida". Não pretendemos, com isso, relegar apenas à escola nem o poder nem a responsabilidade de explicar as identidades sociais, dentre elas, a de 
"ninguém na vida", muito menos a pensamos como capaz de determinar de forma definitiva a vida do sujeito. Contudo, é preciso reconhecer que suas proposições, imposições e proibições criam sentidos, têm "efeitos de verdade", constituem parte significativa das histórias pessoais dos sujeitos. Dessa forma, parece-nos que, por meio de seus instrumentos certificadores, a escola é capaz de produzir níveis de des-legitimidades sociais.

Tal reflexão acarreta que as interpretações em torno da noção de fracasso escolar, que outrora fora concebida como resultado de questões orgânicas e, não obstante patológicas, cederam espaço à compreensão ampliada que considera o/a estudante como sujeito sóciohistórico. Nesse sentido, há o interesse em abrangê-lo/a a partir de seu contexto para, assim, perceber as problemáticas que envolvem o seu acesso e permanência na escola que - tendo em vista a função de inserção à sociedade conferida à educação - resulta em sua exclusão para além dos muros escolares, ou seja, na marginalização social (NAIFF; SÁ; NAIFF, 2008, p. 126). A exclusão e a marginalização representam as diferentes formas de desentendimento quanto à pluralidade presente no cotidiano das escolas e reafirmam a hegemonização do padrão de estudante bem-sucedido/a.

Sobre o caráter social do fracasso escolar em detrimento das questões orgânicas e cognitivas, Senna (2008) aponta que sua trajetória histórica no Brasil evoluiu concomitantemente à história do aspecto social do sujeito. Nesse cenário, eram visados, sobretudo, estudantes do sistema público sobre os quais recaíam os preconceitos que a sociedade brasileira conserva por meio de mecanismos discriminatórios de exclusão e banimento (p.198). Como causas, ele ainda sugere que o fracasso "[...] é produto, ao mesmo tempo, de uma vocação social para a exclusão e de um sem número de mecanismos de banimento que reforçam a condição alienada dos sujeitos marginais, interditando-Ihes a possibilidade de serem sujeitos na esfera pública" (p.199).

Posto isto, é possível compreender que o ideal da escolarização como mecanismo de inserção na vida social, traduzida aqui como "ser alguém", permeia os sentidos conferidos à escola e aos estudos dessa investigação. Dessa forma, é gerado um conjunto de práticas que, por muitas vezes, dificultam o desenvolvimento do sentimento de pertença do/a estudante àquele espaço, tendo em vista o seu possível insucesso por não atingir o ideal de bom/boa estudante estabelecido pela dinâmica pedagógica. Vale relembrar que os/as estudantes da sexta série investigada já estavam de antemão reconhecidos/as pelos déficits de seus conhecimentos. Para a equipe diretiva eles/as não tinham os conhecimentos elementares que os/as permitiram ocupar os lugares daquele nível escolar. Sobre essas problemáticas, Dubet (2003) sublinha:

Os estudantes malsucedidos descobrem pouco a pouco que seu trabalho "não se paga", que eles não conseguem obter resultados honrosos apesar de seus esforços. Descobrem que as exigências dos professores quanto ao "trabalho insuficiente" são apenas um modo de proteger a dignidade deles. Descobrem assim que os esforços para remediar não são eficazes. Então os estudantes decidem não mais fazer o jogo, não mais participar de uma competição na qual eles não têm nenhuma chance de ganhar (DUBET, 2003, p. 41).

Destarte, é perceptível o ideal que se desenvolve em torno do desempenho escolar do sujeito que refletirá sua vida extra-escolar. Esses desdobramentos estabelecem uma relação de proporcionalidade, onde o/a bom/boa estudante será um/a bom/boa cidadão/ã ao passo que 
aquele/a que ocupa a posição oposta cabe a marginalização e a exclusão de não ser alguém por não atingir aos ideais do modelo do primeiro. Ainda, em sua fase escolar, o sujeito não se sente pertencente àquela realidade pode abrir mão - por não se sentir apto - do conjunto de práticas e deveres que constituem os processos de ser e estar estudante.

Ainda na perspectiva da escolarização como mecanismo de aceitação social, é notória também a relação que se faz entre escola e trabalho. Não obstante, é comum a compreensão de que o sucesso na vida escolar garante ao indivíduo as ferramentas necessárias para seu ingresso e permanência no mercado de trabalho. A possibilidade de ascensão social, por meio da escolarização voltada para o mercado, foi tratada por Naif; Sá; Naif (2008), quando evidenciam a relação que o nível e escolaridade estabelece com o desenvolvimento econômico de uma nação:

A vinculação mais objetiva entre escolaridade e renda vai mostrar que existe uma relação diretamente proporcional entre anos de estudo e melhoria nas condições de vida da população (Instituto Brasileiro de Geografia e Estatística [IBGE], 2000). Isso aponta para o fato de que estar na escola, aprendendo, constitui-se em uma possibilidade de mudança nas perspectivas de inserção no mercado de trabalho e consequente maiores chances de geração de renda. (NAIF; SÁ; NAIF, 2008, p.127)

É possível perceber este sentido sobre a escola quando Daniel, outro estudante, em agosto de 2015, descreveu em sua redação: "ser estudante é bom hoje. No nosso futuro a gente só arruma bom emprego se tiver estudo. Só assim se pode ajudar em casa e descobrir as coisas que não sabemos", e discorreu sobre a importância de "ser estudante". Para Daniel, é preciso estudar para se conseguir um bom emprego e, deste modo, transformar a realidade social da família. A explicação de Daniel envolve os diferentes aspectos que a escolarização oferece aos sujeitos sociais, tais como ter um "bom emprego", "orgulhar a família" e ir "descobrindo coisas que não se sabe".

O discente visiona um futuro com melhores possibilidades, sobretudo, profissionais, sendo um bom estudante. A unificação das temporalidades no tempo escolar parece-nos substancial. $O$ sentido construído pelo discente articula uma dinâmica temporal que movimenta três dimensões - passado, presente e futuro -, e a projeção do por vir desempenha um papel motriz, sobretudo, na ideia de um saber que existe a priori que, já posto, deve ser descoberto.

Essa situação nos lembra Delory-Momberger (2008) quando afirma que os sujeitos são seres projetados. Nesse sentido, mesmo a ação mais rotineira traz em si um horizonte infinito de possibilidade, um espaço à frente dela mesma que a lança na existência e lhe dá sua finalidade e sua justificativa. Quando pensamos sobre o tempo privilegiado de preocupação escolar, este concentra-se no futuro, ainda que suas ações o levem a pensar que esteja no presente. É exatamente no futuro que os atos escolares almejam construir cenários diferenciados daqueles que foram vivenciados no presente, sobretudo, se falamos de estrutura de desigualdade econômica, como pode ser observado no contexto estudado.

A expectativa criada por Daniel foi reafirmada por Pedro, em setembro de 2015: "Para mim ser estudante é muito bom. Se eu for um bom estudante será mais fácil arrumar um bom emprego quando terminar. Não quero que meus filhos vivam o que eu ja vivi". Para Pedro os 
diferentes aspectos de sua escolarização estão nitidamente articulados com o sucesso profissional e melhores condições de vida.

Nos depoimentos da professora Catarina, a exemplo do estudante Daniel e Pedro, a educação escolar trabalha de modo a elaborar expectativas profissionais que, no mínimo, possibilitem às/aos estudantes situações iguais ou melhores ao contexto em que viviam em 2015 na cidade de Campina Grande - Paraíba. Ainda que, a perspectiva de Daniel e Pedro em ser um bom estudante, seja a de não abandonar a escola, como fez o irmão de Daniel em decorrência da idade avançada, paternidade e necessidade de ingresso no mundo do trabalho, seu processo educacional os direcionou para uma turma de estudantes que apresentavam desenvolvimentos incompatíveis com o esperado para o sexto ano. Segundo a professora Catarina:

Os estudantes, no geral, em sala de aula, destacam-se pela tranquilidade. Eles conversam pouco nos horários das atividades, contudo, estabelecem uma relação amistosa um com os outros. Mas suas participações, infelizmente, não atendem às exigências da série que ocupam. Parecem estarem em descompasso. Seria aqui seus lugares? (Relatório de pesquisa - Entrevista em Outubro/2015).

Mesmo sendo em forma de pergunta, a professora parece questionar o lugar de pertença desses/as estudantes. Ao reafirmar o descompasso determina uma expectativa que orienta a performatividade assumida para a identidade de estudante de $6 \underline{a}$ série. Não sendo a escola o lugar em que deveriam estar esses sujeitos, onde poderiam estar? Neste sentido, a escola parece funcionar como defensora de uma determinada hierarquização social, garantindo o seu papel de protetora em potencial da estrutura da sociedade.

Refletindo sobre esse aspecto, é possível observar em práticas do cotidiano escolar, a possibilidade de a escola funcionar como espaço de manutenção da ordem vigente e de suas hierarquizações. As expectativas da docente poderiam estar no interior das hierarquizações e classificações sociais, tanto quanto nas práticas e, mais amplamente, nas ações e relações do cotidiano escolar. Neste sentido, elas são as reproduções históricas de comandos sociais, conforme nos sublinhou Certeau (1994).

Dificuldades como as de leitura e escrita por parte dos/as estudantes são as mais citadas pela docente e também pela direção da escola, inclusive foi o principal argumento para criar a turma de aceleração. "Esta questão advém, sobretudo, das políticas de aprovação automática que lança os estudantes a patamares elevados de escolarização sem o pleno conhecimento dos conteúdos pedagógicos de cada etapa", finalizou a professora Catarina, em outubro de 2015. Situação que corrobora, portanto, com o paradoxo entre o acesso universal da escola e seus mecanismos internos de diferenciação e promoção de alguns.

A perspectiva de não desistir da escolarização conforme destacaram os estudantes Rômulo, Daniel e Pedro, ao longo da pesquisa, remete-nos à explicação de que o pertencimento se estabelece não pelos sentidos conferidos ao cotidiano e à trajetória dos sujeitos dentro da escola, mas ocorre com pretensões ao âmbito extraescolar: buscando melhorias em sua condição social e/ou econômica, através da sua preparação para o mundo do trabalho, na tentativa de reverter a situação de desigualdade que incide sobre seu grupo familiar. Sobre o sentido da escola para os estudantes, Valle (1997) ressalta que: 
o educador que olha seu aluno, cidadão do mundo de amanhã, sem saber para onde conduzi-lo, porque todas as saídas parecem, de antemão, fechadas: trabalho, igualdade social, harmonia, felicidade. E aí, o silêncio melancólico da imaginação, a crise do imaginário como crise da razão que inspirava um projeto pedagógico, força a refletir menos na questão da própria razão, do que na incapacidade que parece ser a nossa de projetor um futuro, de persistir em sonhar, mesmo agora ou, sobretudo agora, que sabemos que não podemos escapar do risco de desilusão e do erro (VALLE, 1997, p. 156).

Sobre a perspectiva de um futuro melhor baseado na escolarização, pode-se afirmar que, a função da escola se configura, também pela descrição de Douglas e Pedro, por encaminhar as escolhas profissionais do estudante. Com essa orientação, propicia, em seus limites e possibilidades, a criação de sentidos quanto às expectativas de futuro e transformação. $E$, nesses termos, que nos parecem que discentes percebem a trajetória de tornar-se estudante, as/os docentes e, por sua vez, a escola.

Nesse estudo pensamos ter construído um mosaico panorâmico com as explicações sobre as formas de tornar-se estudante, em emoldurar-se às tarefas pedagógicas e aos deveres, bem como aos fazeres e saberes, de modo a evidenciar as diversas formas escolhidas pelos/as estudantes para a sua realização. Neste cenário, encontramos, nos sentidos criados em torno da identidade de estudante, as táticas criadas por eles/as para adequar-se às demandas do cotidiano da escola que perpassam o desenvolvimento do sentimento de pertença à escola e à sala de aula.

Os dados desse estudo permitem afirmar que, de modo geral, o/a estudante é consciente do que deve fazer para tornar-se estudante, constituindo a escola e a sala de aula como comunidades de pertencimento. Ele/a entende que, para pertencer, deve se adequar às regras da escola, da sala de aula e das interações que mantém com os seus pares e docentes. Porém, o/a discente pode optar em subverter as regras, por exemplo, em não realizar as tarefas, conversar demasiado, movimentando-se de seu lugar e/ou brincar quando o/a professor/a reivindica atenção em decorrência das explicações de conteúdos. Tais atitudes conduzem à percepção docente sobre este sujeito e o aloca em desacordo com as normas de sala de aula e, mais amplamente, da escola. Essa situação é reivindicada para justificar o descompasso etário do/a estudante com a série estudada e pode, ainda, criar justificativas para que docentes e gestores/as o/a considerem um problema, desintegrado/a, inadequado/a, bagunceiro/a, em outras palavras, um/a aluno/a que "não quer nada". Essas justificativas, frequentemente, retroalimentaram os mecanismos que criaram impedimentos ao avanço na educação escolarizada quando questionamos a criação pela equipe diretiva da turma de aceleração.

Para os/as estudantes, nestes casos, resta adequar-se às normas da escola e da professora na sala de aula. Dele/a é exigido que se mantenha sentado/a, em silêncio e realizando seus deveres sob a justificativa de que o conteúdo programático vai conduzi-lo a um saber, à construção de um conhecimento sem o qual não seria possível a ele avançar em sua trajetória escolar e profissional. O/a estudante percebe que é um longo processo que inclui etapas a serem vencidas. Desse modo, na concepção dos sujeitos da pesquisa, tornar-se estudante é um processo construído tanto pela adequação às normas da escola, quanto pela execução de tarefas, nos moldes daquelas orientadas pela professora Carmem. 
Nas narrativas que se seguem, os estudantes Juan, Josiane e Fabiana, em setembro de 2015 , descrevem o que rotineiramente realizam em sala de aula enquanto atividades que vão desde os deveres, passando pelas conversas até as brincadeiras. Eles contam o seguinte:

Eu estudo, faço todos os deveres e outras coisas. Eu também brinco com os meus colegas. Também gosto de vir para o colégio para aprender (Juan, 6 ano)

A professora passa o problema no quadro, eu faço, respondo e dou pra ela. Aí, depois quando tem tempo sobrando que eu acabo o dever, eu e minha prima ficamos jogando cartas, a professora deixa (Josiane, 6ano).

Ser estudante é ser comportada como eu. Eu sou um pouco bagunceira, mas não deixo de fazer o dever, na hora do recreio não dá tempo para fazer nada o máximo é comer, beber água e ir ao banheiro. Da escola, a parte que eu mais gosto é a quadra, eu amo fazer educação física. Na sala, eu converso muito e brinco muito, mas não deixo de fazer o dever. Essa é a minha vida na escola (Fabiana, 60 ano).

Juan menciona a função de aprender da escola, seguida de sua rotina de cumprir os deveres. Além disso, comenta sobre a possibilidade de brincar com seus colegas na escola. A mesma sequência dever-brincar é descrita por Josiane e Fabiana que explica que ainda que converse e brinque não deixa de lado os seus deveres. Com esses excertos, percebemos que Juan, Josiane e Fabiana compreendem que devem realizar as tarefas propostas pela professora Catarina para, então, estar/em liberado/as para outras atividades. O espaço-tempo da escola configura-se como o lugar e momento de aprender permeado pelas conversas, pelas amizades e brincadeiras. Desse modo, as funções e os sentidos da escola configuram-se pela maneira como os/as estudantes constroem o dia a dia em sala de aula incluindo horários, materiais escolares, comportamento, brincadeiras e a ocupação do espaço físico.

O que esses fragmentos de falas e as análises dos mesmos informam é que, para a consolidação do entendimento que o/a discente tem sobre o processo de tornar-se/ser estudante, ele/a sente-se responsável pela construção de seu saber a partir do fazer. Eles/as reconhecem que, para fazer parte do jogo escolar e tornarem-se escolarizados/as, precisam enquadrar-se às normas escolares da aprendizagem exclusivamente mediada pela professora.

Com esses dados, entendemos que o/a estudante é reflexivo/a e crítico/a sobre esse processo e constrói suas próprias noções de sucesso ou de fracasso escolar. Porém, para obter o sucesso, ou seja, a entrada e a permanência escolar, dependerá do uso de astúcias e estabelecimento de táticas de equilíbrio permanente entre o fazer, o dever e o saber. Além disso, foi possível perceber, também, que as funções da escola vão sendo ressignificadas, excluídas ou modificadas por meio do olhar dos sujeitos escolares sobre elas. Assim, passa-se a pensar, não somente em funções, mas em sentidos que refletem as expectativas e as críticas relacionadas à escola como um todo.

A perspectiva de cada sujeito confere, aos processos de tornar-se estudante, um semnúmero de experiências derivadas das interações entre docentes, discentes e comunidade escolar. O somatório dessas experiências e perspectivas sobre as funções e sentidos do fazer, do dever e do saber podem servir à/ao discente durante as diferentes etapas da escolarização levando a que ele/a, através de suas comunidades de pertencimento, possa tornar-se estudante. 
O lugar que carrega essas experiências é a memória para a qual o/a estudante se volta para constituir novas táticas a fim de continuar pertencendo aos diferentes espaços educacionais.

A expectativa de ser alguém na vida, via processo de escolarização, permeia as explicações dos/as estudantes da turma com que desenvolvemos essa investigação sem que os/as mesmos/as analisem criticamente a situação excludente em que se encontram pela matrícula em uma turma à parte.

Com Foucault (2001), compreendemos que essa configuração não objetiva, necessariamente, excluir, mas sim estabelecer um local determinado de circulação daqueles sujeitos, tal como a ideia de quarentena trazida em sua obra "Os anormais". Separa-se para, hipoteticamente, gerar condições igualitárias de acesso e permanência à educação. Contudo, cria-se classes e rótulos que acentuam as diferenças e interditam as possibilidades dos/as menos favorecidos/as. Nessa direção, a esta turma, é destinado um espaço para que as/os discentes permaneçam almejando um futuro promissor ainda que a escola, com sua estrutura pedagógica, não tenha condições de assegurar-Ihes a realização de tais expectativas.

Podemos afirmar que é criada uma escola dentro da outra: a dos/as estudantes com potencial e a dos/as discentes que, por um sem-número de fatores, não se enquadram no padrão esperado pela lógica pedagógica. Ainda, a exclusão social é evidenciada pelas condições em que os/as discentes são percebidos/as pelos/as professores/as que não os/as compreendem como sujeitos do conhecimento. A sala de aula torna-se um espaço de permanência sem que aconteça, efetivamente, produção de conhecimento pela interação entre o professor e o estudante.

De um modo geral, os/as estudantes retratam sua condição na escola orientada por dois eixos de possibilidades, sendo "bom" ou "ruim". Destacam como bom as perspectivas da inclusão social: seja pela escolarização, ingresso ao mercado de trabalho; relações de amizade e novos conhecimentos descobertos. E como ruim, as inúmeras obrigações estabelecidas em pouco tempo para realizá-las, as dificuldades em acompanhar o ritmo de exigências da escola, mesmo sendo uma turma para aceleração; as práticas pedagógicas que os/as reprimem; desrespeito aos seus tempos de aprendizagens e o conhecimento demasiado abstrato. Essa cisão representa o movimento de pertencer dos/das estudantes, porque, se por um lado sentem-se perfeitamente adequados ao espaço escolar pela possibilidade interativa entre eles/elas - a amizade - por outro, estão em situação de exclusão pela impossibilidade de acompanhar o currículo previsto para o 6 ano, ou pelo domínio das capacidades de leitura e escrita.

Em linhas gerais, percebemos e analisamos dados que remetem à noção evidenciada por Bourdieu; Champagne (1998) sobre os/as excluídos/as no interior. Diz respeito aqueles/àquelas estudantes que permanecem na escola, com diferentes concepções de ser estudante, ao pertencer a um processo que, lenta e silenciosamente, os/as exclui dos processos considerados ordinários nos ciclos da escolarização.

\section{CONSIDERAÇÕES FINAIS}

Sobre a possibilidade de investigar o contexto de sala de aula a partir dos estudos do cotidiano em educação, é possível considerar que estes permitem um olhar próximo da realidade 
produzida pelos sujeitos escolares. Da mesma forma, tal abordagem fornece pistas para o entendimento do que se vivencia no espaço-tempo de sala de aula. Isto se dá pela leitura daquilo que por ser reiteradamente performado no dia a dia, é comumente percebido como ordinário. Nesse sentido, acreditamos que as discussões propostas aqui a partir dos dados produzidos com a pesquisa nos permitiram interrogar as interações e compreender, sobretudo, os significados dos processos estabelecidos na escola a partir de um viés da complexificação.

Por outro lado, configurou-se de forma constante neste trabalho, como parte do procedimento dialético a relação indissociável entre pesquisadora e estudantes, de forma a considerar nesta a necessária sensibilidade cultural para lidar com procedimentos interativos. Isto se dá no intuito de interrogar as práticas e as/os praticantes a partir dos/as próprios/as agentes da ação. Nesse sentido, como componente da teoria sobre o tornar-se estudante, destacamos o envolvimento da equipe de pesquisa com o universo investigado e como este foi construído/percebido pelos sujeitos. Da mesma forma, apresentam-se diferentes concepções sobre as funções e os sentidos da escola descritos por meio da ação pedagógica de docentes e estudantes. A compreensão destes/as últimos/as se expressa, ainda, através da memória como um constructo social descrita pelos/as participantes como representações mentais que fornecem interpretações múltiplas em diversos níveis para conhecer o que eles/as destacam para si e para os/as outros/as como relevantes para explicar os processos escolares que os/as tornam estudantes.

A oportunidade de aprender com o espaço-tempo da escola através das interpretações produzidas pelos sujeitos escolares envolvidos no estudo, exigiu à análise preliminar de dados e relatos o compromisso com seus sentidos. Longe de ser uma simples menção aos acontecimentos ocorridos, nossas considerações tendem e pretendem tornar-se ferramentas de reflexão sobre a problemática da exclusão vigente no sistema educacional. Ao mesmo tempo, tencionamos informar aos sujeitos da escola, sobretudo às/aos professoras/es, a respeito da influência das práticas vivenciadas no universo da escola sobre o desenvolvimento discente e abordar a importância de se buscar metodologias que visem a promoção da qualidade dos conhecimentos produzidos por todos/as no interior das salas de aula.

Com a perspectiva do pertencimento, salientamos que a rotulação de bons/boas ou maus/más estudantes garante a umas/uns as ferramentas para seus/suas desenvolvimentos pedagógicos e a outros/as, meras formas de amenizar suas sugeridas "incapacidades", sem esperanças de enquadrar-se ao, que é considerado como sendo, currículo "normal" da escola.

A perspectiva do/a estudante, refletida com as respostas escritas, permitiu compreender, ainda, o que é o processo de escolarização para eles/as. A importância mencionada nas descrições não foi observada no contexto de sala de aula, uma vez que os/as mesmos/as permanecem sem atividades que visem a produção do conhecimento para incluí-los/as efetivamente no contexto educacional. A exclusão mostra-se velada, quando o acesso é facilitado, mas, em contrapartida, a permanência se estabelece baseada em mecanismos de segregação dos/as consideradas/os menos aptos/as. Desconfigura-se, portanto, o ideal de escola democrática e acessível a todos/as.

Salientamos, ainda, que, apesar de a garantia à matrícula ser concedida deliberadamente, as práticas da escola, pelo sistema que a envolve, demandam meios de exclusão e separação entre os sujeitos que a frequentam. A partir de uma organização que não se adequa às pluralidades e, desta forma, desconsidera a complexidade e heterogeneidade do fenômeno do ensinar e aprender, gera-se a limitação a etapas predefinidas e conteúdos pré-selecionados. 
Dessa forma, lança-se, exclusivamente, sobre o/a estudante a responsabilidade sobre o êxito de sua escolarização, uma vez que se é propagado o ideal de que a escola está disponível e acessível de forma universal.

Em linhas gerais, os resultados desse trabalho, podem servir de suporte para entendimento das práticas escolares a partir dos/as próprios/as praticantes. Além disso, de certa forma, buscamos oferecer possibilidades de mudanças nos espaços-tempos de ensinar e aprender.

Ao concordamos com Caetano (2016), sublinhamos que o cotidiano é lócus no qual ocorre a interação entre as forças que se (re)articulam e (re)negociam dinamicamente. Nessas interações, a criatividade pareceu possibilitar aos sujeitos participantes da pesquisa a criação de sentidos que significaram e projetaram suas práticas mesmo frente às forças que, de forma coercitiva, buscaram enquadrá-los em formas padronizadas de fracasso ou sucesso. Sendo assim, idealizamos que os conceitos de identidade, pertencimento, resiliência, dever, saber, fazer assim como as funções e os sentidos da escola refletidos aqui possam se constituir como referenciais para que as ações pedagógicas favoreçam a autonomia e a criticidade para cada discente em seus processos de ser e tornar-se estudante.

\section{REFERÊNCIAS}

ALVES, N. (2010). Sobre as razões das pesquisas nos/dos/com os cotidianos. In: GARCIA, Regina Leite (Org.). Diálogos cotidianos (pp.67-80). Petrópolis, RJ/Brasil: FAPERJ-DP\&A.

- (2001). Decifrando o pergaminho: o cotidiano das escolas nas lógicas das redes cotidianas. In: OLIVEIRA, I. B. de; ALVES, N. (Org.). Pesquisa no/do cotidiano das escolas: sobre redes de saberes (pp. 13-37). Rio de Janeiro, RJ: DP\&A.

BOURDIEU, P; CHAMPAGNE, P. (1998). Os excluídos do interior. In: NOGUEIRA, M. A; CATANI, A. (Org.). Escritos de Educação (pp. 217-228). Petrópolis, RJ: Vozes.

BRASIL (2016). Resolução No. 510, DE 07 DE ABRIL DE 2016. Brasília, Conselho Nacional de Saúde.

CAETANO, M. (2016). Performatividades reguladas: heteronormatividades, narrativas biográficas e educação. Curitiba, PR: Apprir.

CASTRO, P. A. de. (2016). Tornar-se aluno - identidade e pertencimento: perspectivas etnográficas. Campina Grande, PB: EDUEPB.

CERTEAU, M. (1994). A invenção do cotidiano: 1. Artes de fazer. Petrópolis, RJ: Vozes.

DELAMONT, S. (1987). Interaç̧ão na sala de aula. Lisboa, Portugal: Livros Horizonte.

DELORY-MOMBERGER. C. (2008). Biografia e educação: figuras do indivíduo-projeto. Natal, RN: EDUFRN.

DUBET, F. (2003). A escola e a exclusão. Cadernos de Pesquisa (119), 29-45.

FOUCAULT, M. (2001). Os Anormais: curso no Collège de France (1974-1975). São Paulo, SP: Martins Fontes.

GARCIA, R. L. (2003). Método, métodos, contramétodos. São Paulo, SP: Cortez.

. (2001). Reflexões sobre a responsabilidade social do pesquisador. In: MOREIRA, A. F. [et.

al.] (Org.). Para quem pesquisamos. Para quem escrevemos: o impasse dos intelectuais (pp. 11-36). São Paulo: Cortez.

HALL, S. (2003). A identidade cultural na pós-modernidade. Rio de Janeiro: DP\&A.

NAIFF, L. A. M.; SÁ, C. P. de; NAIFF, D. G. M. (2008). Preciso estudar para ser alguém: memória e representações sociais da educação escolar. Paidéia, 18 (39), 125-138. 
OLIVEIRA, I. B. de. (2007). Aprendendo nos/dos/com os cotidianos a ver/ler/ouvir/sentir o mundo. Educação e Sociedade, 28(98), 47-72.

SARMENTO, M. J. (2002). Infância, exclusão social e educação como utopia realizável. Educação \& Sociedade, 23(78), 265-283.

SENNA, L. A. G. (2008). Formação docente e educação inclusiva. Cadernos de Pesquisa, 38(133), 195-219.

SOUSA, C. P. de. (1999). Limites e possibilidades dos programas de aceleração de aprendizagem. Cadernos de Pesquisa, (108), 81-99.

STEINBERG, S.; KINCHELOE, J. (1997). Students as researchers: creating classrooms that matter. New York, Estados Unidos: Taylor Print on Dema.

VALLE, L. (1997). A escola imaginária. Rio de Janeiro, RJ: DP\&A. 